\title{
Characterization of the Glutamate Transporter in Retinal Cones of the Tiger Salamander
}

\author{
Scott Eliasof and Frank Werblin \\ University of California, Berkeley, California 94720
}

\begin{abstract}
L-Glutamate elicits an inwardly rectifying current at hyperpolarized potentials in isolated retinal cones of the tiger salamander, as measured under whole-cell patch clamp. Evidence presented in this article supports the notion that cones possess a high-affinity glutamate transporter. This glutamate-elicited current shows no desensitization over a period of several minutes, and has an affinity $\left(K_{m}\right)$ of $10 \mu \mathrm{M}$. The inward current is mimicked by the amino acids L-aspartate, $D$-aspartate, L-cysteate, and to a lesser extent D-glutamate. It is neither blocked by the glutamate receptor antagonists kynurenic acid (1 mM), 6-cyano-7-nitroquinoxaline-2,3-dione (100 $\mu \mathrm{M})$, or 2-amino-5-phosphonovalerate $(100 \mu \mathrm{M})$, nor elicited by the glutamate receptor agonists $(100 \mu \mathrm{m}$ each $)$ kainate, quisqualate, NMDA, or 2-amino-4-phosphonobutyrate. The glutamate-elicited current was reduced by the glutamate transport blockers dihydrokainate (DHKA), DL-threo- $\beta$-hydroxyaspartate $(\beta \mathrm{HA})$, and L-trans-pyrrolidine-2,4-dicarboxylic acid. When glutamate was present on both sides of the membrane, the blockers reduced both uptake and release; the blocker-sensitive current as a function of membrane potential represents the transport current-voltage relation $(1-V)$, and the reversal potential of the $\vdash V$ represents the transporter equilibrium potential. This potential was a function of the equilibrium potential for glutamate. DHKA and $\beta \mathrm{HA}$ depolarized horizontal cells in a retinal slice, and abolished their light responses, suggesting that in the absence of glutamate transport, glutamate concentrations in the cleft rise to a level that saturates the postsynaptic receptors. The high capacity of the cone glutamate transporter is well suited for the rapid removal of glutamate from the synaptic cleft required for the signaling of a light onset to postsynaptic cells.

[Key words: glutamate, transport, photoreceptors, retina, electrophysiology, horizontal cells]
\end{abstract}

Photoreceptors inform the rest of the visual system of a light flash by a reduction in the concentration of the synaptic transmitter glutamate at their terminals (Trifonov, 1968; Ayoub et al., 1989; Copenhagen and Jahr, 1989). Since no enzymes exist extracellularly that will degrade the transmitter signal, the termination of transmitter release requires either the diffusion of glutamate into the bulk medium, or the uptake of glutamate through a high-affinity transporter. A high-affinity glutamate

\footnotetext{
Received Apr. 9, 1992; revised July 21, 1992; accepted July 23, 1992.

We thank Drs. S. S. Miller and W. G. Owen for their helpful comments and suggestions on the manuscript. This work was supported by a grant from NIH (EY-00561).

Correspondence should be addressed to Frank Werblin, 145 LSA, University of California, Berkeley, CA 94720.

Copyright (C) 1993 Socicty for Neuroscience $0270-6474 / 93 / 130402 \cdot 10 \$ 05.00 / 0$
}

transporter has been shown to exist in retinal glial cells (Brew and Attwell, 1987), but since glial processes have not been found to enter the invaginations of rods and cones (Lasansky, 1973), uptake of glutamate into glia will first entail the diffusion of glutamate out of the photoreceptor invagination. Given the rapid kinetics of the light onset in postsynaptic cells (Copenhagen et al., 1983), such diffusion may be inadequate.

A more rapid and efficient form of removal could be provided by a transporter located at the photoreceptor terminal itself. Presynaptic high-affinity transporters have been found in synapses associated with the release of not only glutamate, but many other transmitters such as noradrenaline, dopamine, 5-HT, and GABA (Iversen, 1971). These transporters allow not only the rapid removal of a transmitter, but also an efficient source for molecular recycling. This is of particular importance in cones, where transmission is tonic rather than phasic.

Such a high-affinity presynaptic transporter in photoreceptors has been suggested by uptake studies in goldfish (Marc and Lam, 1981). More recently, measurements of a glutamate-elicited current in turtle photoreceptors were shown to be consistent with an electrogenic glutamate transporter (Tachibana and Kaneko, 1988). However, Sarantis et al. (1988) suggested that the glutamate-elicited current in cones of the tiger salamander was due to a glutamate-elicited chloride conductance.

We have reinvestigated the glutamate-elicited current in the retinal cone of the tiger salamander, and conclude that the current is not generated by any known glutamate receptor-gated conductance, but rather by an electrogenic transporter. Moreover, we show that glutamate transport in the outer retina is essential for proper synaptic transmission to horizontal cells, which lie postsynaptic to the cone.

\section{Materials and Methods}

Preparation. Whole-cell patch recordings (Hamill et al., 1981) were made from horizontal cells in the retinal slice, and from isolated retinal cones of the larval tiger salamander (Ambystoma tigrinum). Isolated cones were prepared as follows. Whole retinas were incubated in Ringer's containing $0.1 \mathrm{U} / \mathrm{ml}$ papain (Worthington Biochemical, Freehold, $\mathrm{NJ}$ ) for $20 \mathrm{~min}$ at $30^{\circ} \mathrm{C}$, quenched in Ringer's containing $1 \mathrm{mg} / \mathrm{ml}$ bovine albumin (Sigma Chemical, St. Louis, MO) for $15 \mathrm{~min}$ at $4^{\circ} \mathrm{C}$, and rinsed three times in normal Ringer's over the next $30 \mathrm{~min}$ at $4^{\circ} \mathrm{C}$. The retina was then chopped into roughly square pieces $250 \mu \mathrm{m}$ on a side, and gently triturated with a fire-polished Pasteur pipette. The triturated retina was stored in $1.5 \mathrm{ml}$ of Ringer's at $4^{\circ} \mathrm{C}$ in a polypropylene centrifuge tube for 4-8 hr. Just prior to an experiment, $100 \mu \mathrm{l}$ of the triturated retina was placed in a Ringer's filled $750 \mu$ l glass chamber cleaned with acidified alcohol. All cones recorded from were easily identified, possessing inner and outer segments, a cell body, and a "tuft" of processes at the proximal end of the soma (see Fig. 1). When these processes were lacking, we usually could not elicit a current with the application of glutamate. We have therefore restricted our studies to cells containing processes. 


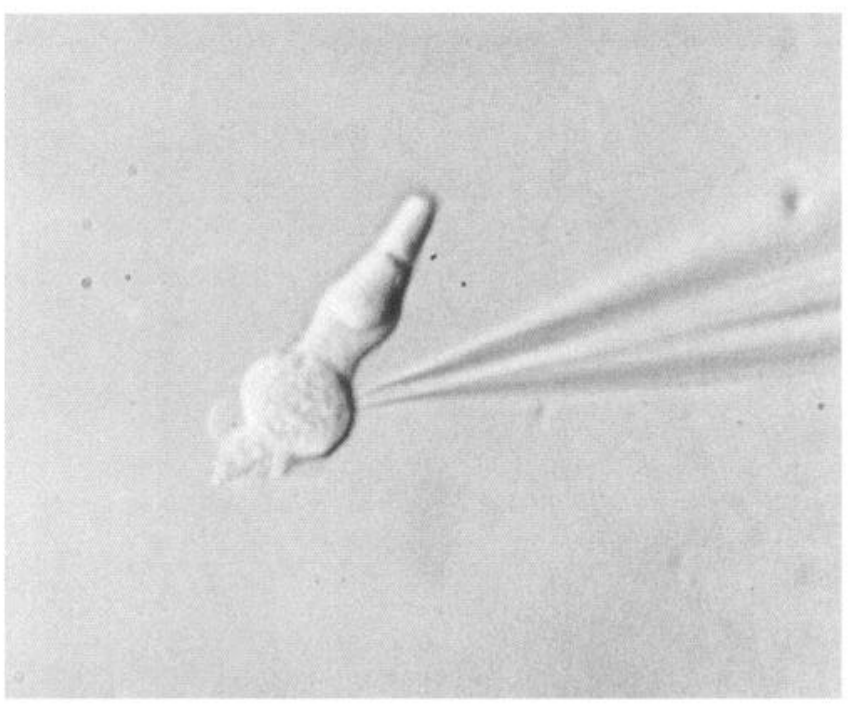

Figure 1. Photomicrograph of an isolated cone. The inner segment, outer segment, cell body, and tuft of processes on the distal end of the cell body are all present. A patch electrode sealed to the cone's somatic membrane is also shown.

The retinal slice preparation has been described previously (Werblin, 1978). Horizontal cells in the slice were identified by their characteristic morphology and their large hyperpolarization to subsaturating light flashes. Their morphology was determined by staining them with $1 \%$ Lucifer yellow, and viewing the cells with an UV epiilluminator at the end of the experiment.

Recording system. Cells were viewed under a Zeiss $40 \times$ water immersion lens. Electrodes were made of borosilicate glass (TW150F-4, World Precision Instruments, Sarasota, FL) pulled using a Brown and Flaming type puller (P-87, Sutter Instruments, Novato, CA), and had a measured resistance of less than $5 \mathrm{M} \Omega$. Series resistance was measured to be less than $15 \mathrm{M} \Omega$. Currents and voltages were amplified using a List L/M EPC7 (Medical Systems Inc., Greenvale, NY) and digitized at a rate of either 1 or $5 \mathrm{KHz}$ using a Data Translations DT-2801A interface (Greenvale, NY). Data were stored and analyzed using an IBM PC AT.

Liquid junction potentials were corrected for as described by Fenwick et al. (1982). Briefly, a fine-tipped electrode filled with $2.5 \mathrm{M} \mathrm{KCl}$ and a resistance of $100 \mathrm{M} \Omega$ was placed in the bath containing control Ringer's, and the pipette potential was set to $0 \mathrm{mV}$. The bath solution was then changed to the intracellular solution, and the new pipette potential was noted. This is the junction potential. This potential was corrected for by setting the pipette potential to the junction potential prior to obtaining a seal on a cell.

Solutions. Extracellular solutions were perfused into the bath by means of a push-pull syringe apparatus through two 18 gauge needles, cut off before the tip. At least $5 \mathrm{ml}$ of a solution was applied, at a rate of approximately $5 \mathrm{ml} / \mathrm{min}$, before any recording was made. Normal (control) Ringer's consisted of (in mм) $108 \mathrm{NaCl}, 2.5 \mathrm{KCl}, 1 \mathrm{CaCl}_{2}, 1 \mathrm{MgCl}_{2}$, 5 HEPES, and 3 glucose. The pH was set to 7.75 by the addition of $\mathrm{NaOH}$. Drugs were added without substitution.

All electrode solutions contained (in mM) 4 HEPES, $1 \mathrm{Na}_{2} \mathrm{ATP}, 0.1$ $\mathrm{Na}_{3}$ GTP, $1.27 \mathrm{~K}_{4}$ BAPTA, $0.1 \mathrm{CaCl}_{2}$, and 1 sodium glutamate. When recording from cones, the solution contained $116 \mathrm{KCl}$. When recording from horizontal cells, the solution contained $50 \mathrm{KCl}$ and $66 \mathrm{~K}$-gluconate. The $\mathrm{pH}$ was set to 7.4 by the addition of $\mathrm{KOH}$.

All drugs were purchased from Sigma (St. Louis, MO) except HEPES (CalBiochem, La Jolla, CA), 6-cyano-7-nitroquinoxaline-2,3-dione (CNQX; Research Biochemicals, Natick, MA), and L-trans-pyrrolidine2,4-dicarboxylic acid (tPDC; Tocris Neuramin, Bristol, UK).

Derivation of the transporter equilibrium potential. The flow of ions and glutamate through the transporter is a function of both the electrical and chemical potentials for each transported species. At equilibrium, the sum of the electrochemical potentials will be zero. That is,

$$
\sum_{x}\left(n_{x} R T \ln \frac{[x]_{\text {in }}}{[x]_{\text {out }}}+n_{x} z_{x} F V_{\mathrm{eq}}\right) k_{x}=0
$$
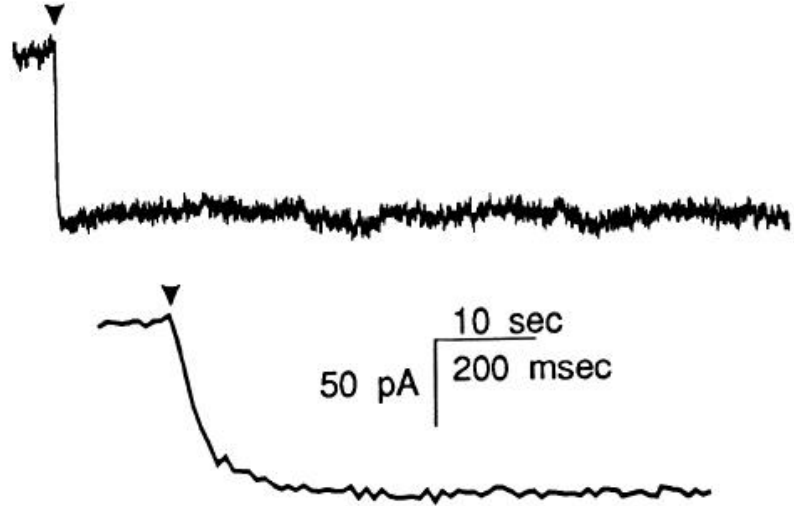

Figure 2. Current response of a cone to pressure injection of $100 \mu \mathrm{M}$ L-glutamate while the membrane potential was clamped to $-60 \mathrm{mV}$. Arrowheads indicate the time of application. The response is shown on a slow time scale and the onset at a faster time scale. No desensitization is evident.

where $x$ is one of the ions (or glutamate) that flows through the transporter, $n_{x}$ is the stoichiometrical coefficient for the $x$ th ion, $z_{x}$ is the valence of the $x$ th ion, and $k_{x}$ is the directional coefficient for the $x$ th ion, defined to be +1 for inward flow and -1 for outward flow. $V_{\mathrm{eq}}$ is the equilibrium potential of the transporter. Since all ions and glutamate are charged, we can substitute in the standard definition for the Nernst equilibrium potential. That is, since

$$
E_{x}=-\frac{1}{z_{x}} \frac{R T}{F} \ln \frac{[x]_{\text {in }}}{[x]_{\text {out }}},
$$

then, by substitution into Equation 1, and rearranging:

$$
V_{\mathrm{eq}}=\frac{\sum k_{x} n_{x} z_{x} E_{x}}{\sum k_{x} n_{x} z_{x}}
$$

This equation simply states that the equilibrium potential for the transporter is the weighted sum of the equilibrium potential for each ion or glutamate. $\Sigma k_{x} n_{x} z_{x}$ is the total charge transported.

\section{Results}

Response to a sustained glutamate application does not decline Figure 2 shows the current generated when $100 \mu \mathrm{M}$ L-glutamate is pressure ejected for over a minute near the terminal of a voltage-clamped, isolated cone. The onset of the current is also shown at a faster time scale. In this and four other cells, we measured no significant decline in the current after $2 \mathrm{~min}$. The current at 2 min was $103 \pm 2 \%$ (mean $\pm \mathrm{SD}$ ) of the initial peak.

\section{Glutamate-elicited current is voltage dependent}

Since the glutamate-elicited current did not decay, in subsequent experiments solutions were applied through bath perfusion. This allowed the application of many different substances in a single cell. Figure 3 shows the effect of bath application of L-glutamate on cones. The elicited current at a given potential is measured as the difference in the steady state current recorded in the presence and absence of $100 \mu \mathrm{M}$ L-glutamate while the cone is under voltage clamp. In order to measure the current at various potentials, the membrane is held at $-60 \mathrm{mV}$, and stepped to each potential; the steady state current is the average current measured between 70 and $80 \mathrm{msec}$ after the membrane was stepped to a new potential. Figure $3 A$ shows the clamp currents in the absence and the presence of $100 \mu \mathrm{M}$ glutamate. Figure $3 B$ shows the current-voltage curve calculated from the difference of currents such as those shown in Figure $3 A$, averaged from 43 different cells. This curve is inwardly rectifying, and varied 


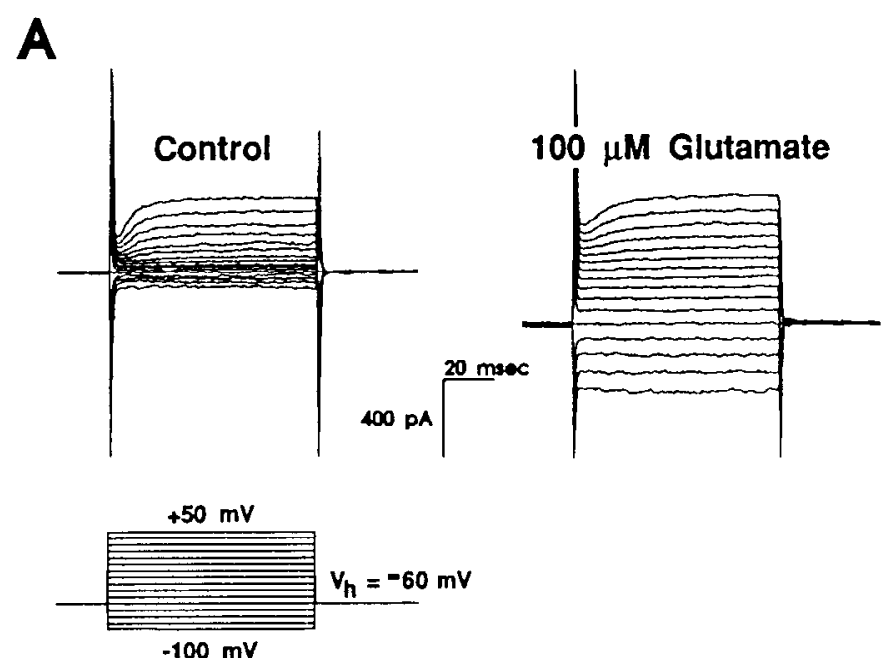

B

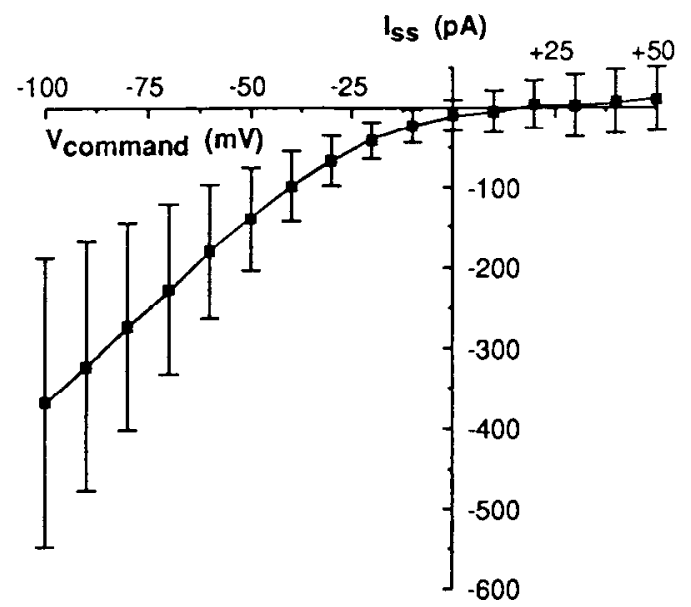

Figure 3. Generation of steady state current-voltage curves elicited by bath application of $100 \mu \mathrm{M}$ L-glutamate. $A$, Currents measured under voltage clamp. $V_{\text {hold }}=-60 \mathrm{mV}$. Traces are shown in both control Ringer's and in $100 \mu \mathrm{M}$ L-glutamate. Note that the holding current became more inward when glutamate was applied. $B$, Current-voltage curve resulting from the subtraction of the steady state current in control and glutamate in 43 cells. Error bars indicate SD. Steady state range was over the range of $70-80 \mathrm{msec}$ following the voltage step.

greatly in size from cell to cell, ranging from $800 \mathrm{pA}$ to $150 \mathrm{pA}$ at $-100 \mathrm{mV}$. In some cases, there was an outward current at potentials more positive than $0 \mathrm{mV}$, but the averaged current does not show any significant outward current at positive potentials up to $+40 \mathrm{mV}$.

\section{Glutamate-elicited current is concentration dependent}

Various doses of L-glutamate, from $1 \mu \mathrm{M}$ to $1 \mathrm{mM}$, were bath applied while the cone membrane potential was maintained at $-60 \mathrm{mV}$. In these cells, the pipette contained no glutamate, so that the thermodynamic equilibrium potential remained infinite for all extracellular glutamate concentrations ([Glu $\left.]_{o}\right)$. The resulting current was subtracted from the baseline current (when extracellular glutamate was absent) and normalized such that the response to $1 \mathrm{~mm}$ glutamate was set to 1 . Data was averaged from four cells and fit to the Michaelis-Menten equation. This is shown in Figure 4. The glutamate concentration that produced the half-maximum response $\left(K_{m}\right)$ is $11 \mu \mathbf{M}$.

\section{Normalized Current}

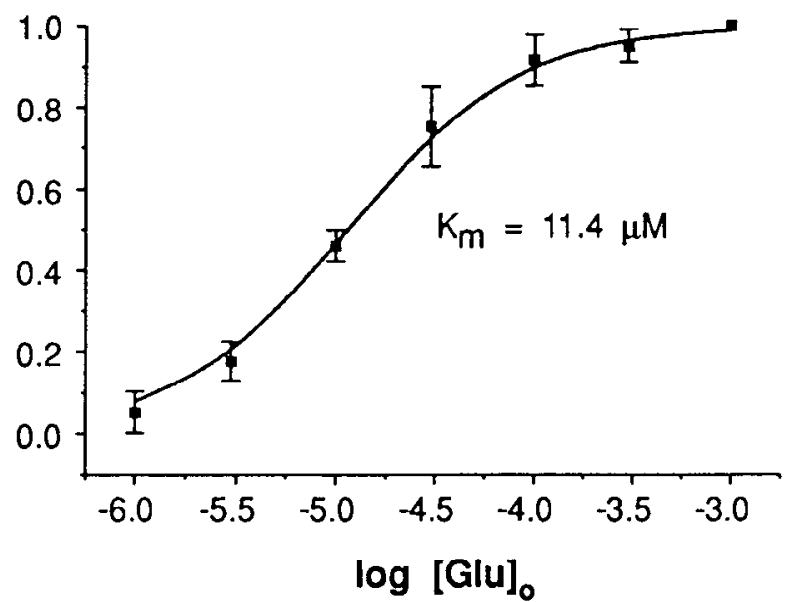

Figure 4. Dose-response relationship of the glutamate-elicited current. Data are normalized from four cells. Smooth curve is the Michaelis-Menten equation, with $K_{m}=11.4 \mu \mathrm{M}$.

\section{Other amino acids elicit a similar current}

We were also able to elicit a similar current with the application of several other amino acids known to affect glutamate transporters. Figure 5 shows the effects of $100 \mu \mathrm{M}$ L-glutamate, D-glutamate, L-aspartate, D-aspartate, and L-cysteate, all in the same cell. All five of these substances were effective, with a relative amino acid sensitivity of L-glutamate $>$ L-cysteate $>$ L-aspartate $\approx$ D-aspartate $\gg$ D-glutamate. Similar results were secn in a total of six cells. This agonist sensitivity profile is consistent with many glutamate transporters, including the transporter described in photoreceptors by Tachibana and Kaneko (1988).

\section{Glutamate-elicited current inconsistent with glutamate receptor pharmacology}

Glutamate receptor antagonists are ineffective. To examine whether the glutamate-elicited current was pharmacologically consistent with the presence of a glutamate receptor, we first measured the effect of the glutamate receptor antagonists on the glutamate-elicited current. Substances were bath applied in the

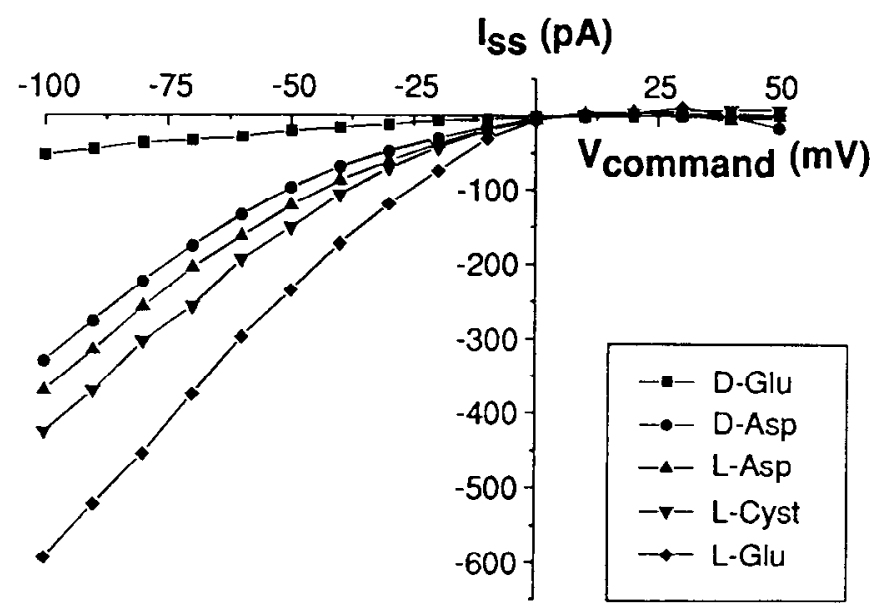

Figure 5. Steady state, current-voltage curves generated in the same cell by application of (100 $\mu \mathrm{M}$ each) $\mathrm{L}$-glutamate, L-aspartate, D-aspartate, L-cysteate, and D-glutamate. 

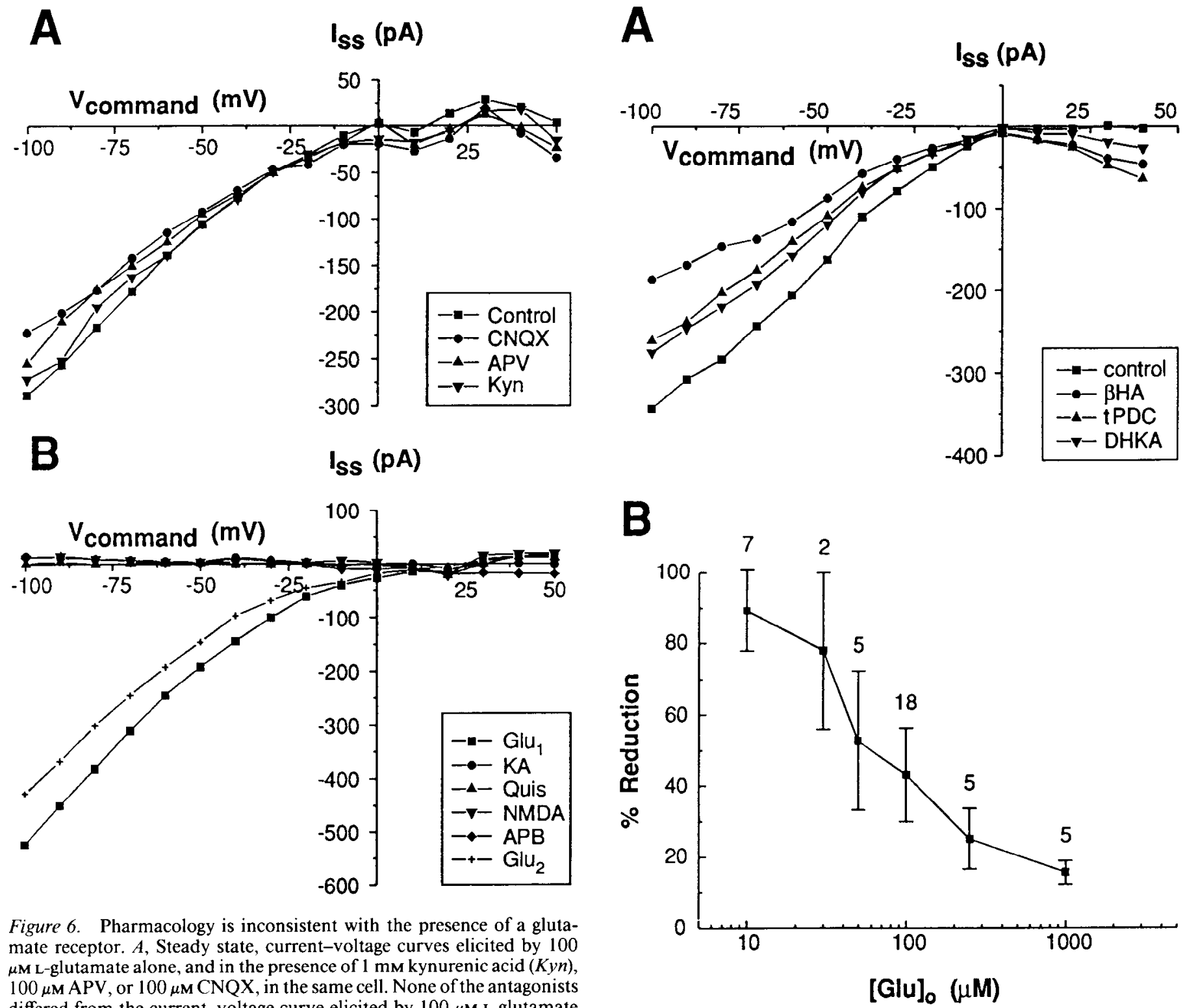

Figure 6. Pharmacology is inconsistent with the presence of a glutamate receptor. $A$, Steady state, current-voltage curves elicited by 100 $\mu \mathrm{M} \mathrm{L}$-glutamate alone, and in the presence of $1 \mathrm{~mm}$ kynurenic acid $(K y n)$, $100 \mu \mathrm{M} \mathrm{APV}$, or $100 \mu \mathrm{M} \mathrm{CNQX}$, in the same cell. None of the antagonists differed from the current-voltage curve elicited by $100 \mu \mathrm{M}$ L-glutamate alone. $B$, Steady state, current-voltage curves elicited by $100 \mu \mathrm{M} \mathrm{L-gluta-}$ mate $\left(G l u_{l}\right), 100 \mu \mathrm{M}$ kainate $(K A), 100 \mu \mathrm{M}$ NMDA (plus $10 \mu \mathrm{M}$ glycine), $100 \mu \mathrm{M} \mathrm{APB}$, and $100 \mu \mathrm{M}$ quisqualate (Quis). L-Glutamate $(100 \mu \mathrm{M})$ was applied a second time at the end of the experiment $\left(G / u_{2}\right)$ to test for the continued viability of the glutamate-elicited current. Only L-glutamate elicited a measurable current.

presence of $100 \mu \mathrm{M}$ glutamate, and steady state currents were derived as the difference of the response to glutamate with the antagonist minus control. The results are compared with the difference current of glutamate alone, and are shown in Figure $6 A$. Neither $1 \mathrm{~mm}$ kynurenic acid, $100 \mu \mathrm{M}$ 2-amino-5-phosphonovalerate (APV), nor $100 \mu \mathrm{M}$ CNQX had any effect on the glutamate-elicited current. These concentrations are considerably higher than would be necessary had the glutamate-elicited current been generated by a known glutamate receptor. Similar results were seen in six cells.

Glutamate receptor agonists are ineffective. We next studied whether glutamate receptor agonists applied alone could mimic the current elicited by $100 \mu \mathrm{M} \mathrm{L-glutamate.} \mathrm{Figure} 6 B$ shows the effects of glutamate and the glutamate receptor agonists (100 $\mu \mathrm{M}$ each) kainate, quisqualate, NMD^ (in addition to $10 \mu \mathrm{M}$

Figure 7. Pharmacology consistent with the presence of a glutamate transporter. $A$, Steady state current-voltage curves elicited by $100 \mu \mathrm{M}$ L-glutamate (control), and by $100 \mu \mathrm{M} \mathrm{L}$-glutamate in the presence of 1 mм DHKA, $100 \mu \mathrm{M} \beta \mathrm{HA}$, and $100 \mu \mathrm{M}$ tPDC. $B$, Percentage reduction by $1 \mathrm{~mm}$ DHKA as a function of extracellular $\mathrm{L}$-glutamate concentration ([Glu], . Declining reduction with higher glutamate concentrations suggests that DHKA is a competitive blocker. Data collected from 28 cells. Points represent mean, and error bars represent SDs. Numbers above error bars represent the number of cells used for that data point.

glycine), and 2-amino-4-phosphonobutyrate (APB) all on the same cell. Only glutamate evoked an inward current. A second application of glutamate was nearly as effective in eliciting a current, suggesting that the absence of any response to receptor agonists was not due to the rundown of the glutamate-elicited effect. Similar results were seen in seven cells.

\section{Glutamate transport blockers reduce glutamate-elicited current}

We examined the effects of three substances which act as specific blockers of the glutamate transporter: dihydrokainate (DHKA), DL-threo- $\beta$-hydroxyaspartate $(\beta \mathrm{HA})$, and tPDC (Balcar and Johnston, 1972; Johnston et al., 1979; Bridges et al., 1991). Figure $7 A$ shows the current elicited when $100 \mu \mathrm{M}$ L-glutamate 


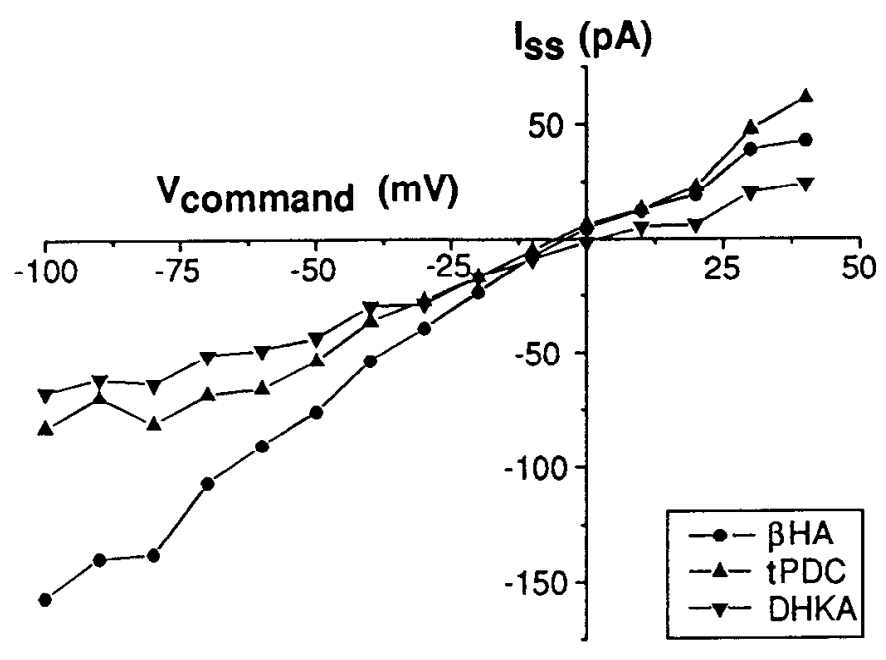

Figure 8. Steady state current through the transporter as a function of membrane potential, blocked by the transport blockers $1 \mathrm{~mm}$ DHKA, $100 \mu \mathrm{M} \beta \mathrm{HA}$, and $100 \mu \mathrm{M}$ tPDC, when L-glutamate is present on both the outside $(100 \mu \mathrm{M})$ and inside $(1 \mathrm{mM})$ of the cell. The curves were generated by subtracting the current-voltage curve when the blocker was absent minus when the blocker was present, and thus represents the current blocked.

was applied alone (control) and in the presence of $1 \mathrm{~mm}$ DHKA, $\beta \mathrm{HA}$, or $\mathrm{PDC}$. In this single cell, all three blockers reduced the current elicited by application of $100 \mu \mathrm{M} \mathrm{L}$-glutamate, as measured over the potential range of $-100 \mathrm{mV}$ to $0 \mathrm{mV}$. As a control, the response to glutamate alone was tested several times over the course of the experiment, and no time-dependent reduction was observed. By measuring the decrease in response to $100 \mu \mathrm{M} \mathrm{L}$-glutamate over the entire voltage range, we found that $1 \mathrm{~mm}$ DHKA reduced the response by $43 \pm 13 \%(N=17)$, $100 \mu \mathrm{M} \beta \mathrm{IIA}$ by $57 \pm 14 \%(N=13), 1 \mathrm{~mm} \beta \mathrm{HA}$ by $68 \pm 15 \%$ $(N=5), 100 \mu \mathrm{M}$ tPDC by $33 \pm 16 \%(N=10)$, and $1 \mathrm{~mm} \mathrm{tPDC}$ by $57+13 \%(N=4)$. Furthermore, the block by DHKA decreased with increasing extracellular glutamate concentration, suggesting that it competes with glutamate at the same binding site. This is shown in Figure $7 B$. Reduction by DHKA was measured in a total of 28 cells, with extracellular glutamate concentrations ranging from $10 \mu \mathrm{M}$ to $1 \mathrm{~mm}$. We did not look at similar dose dependence with either $\beta \mathrm{HA}$ or tPDC.

All three inhibitors are conformational analogs of glutamate; it is therefore possible that they are acting not at the transporter, but at glutamate receptor sites. To test for an action of these substances that is not transport specific, we also applied them in the absence of extracellular glutamate. With no glutamate present in the patch pipette, and with blocker concentrations as high as $1 \mathrm{~mm}$, we did not see an effect of any of the blockers over the entire potential range of -100 to $+40 \mathrm{mV}(N=9)$.

\section{Blockers reveal current-voltage curve for the transporter}

Since it appears that DHKA, $\beta \mathrm{HA}$, and tPDC are acting specifically to block glutamate transport, the current reduced by the blockers is the current through the transporter. To the extent that the blockers' effects are voltage independent, a plot of the blocker-sensitive current as a function of membrane potential is a measure of the transporter's current-voltage relation. We have already shown, however, that the block effect is not complete, and so the measured current represents only some fraction of the total transport current.

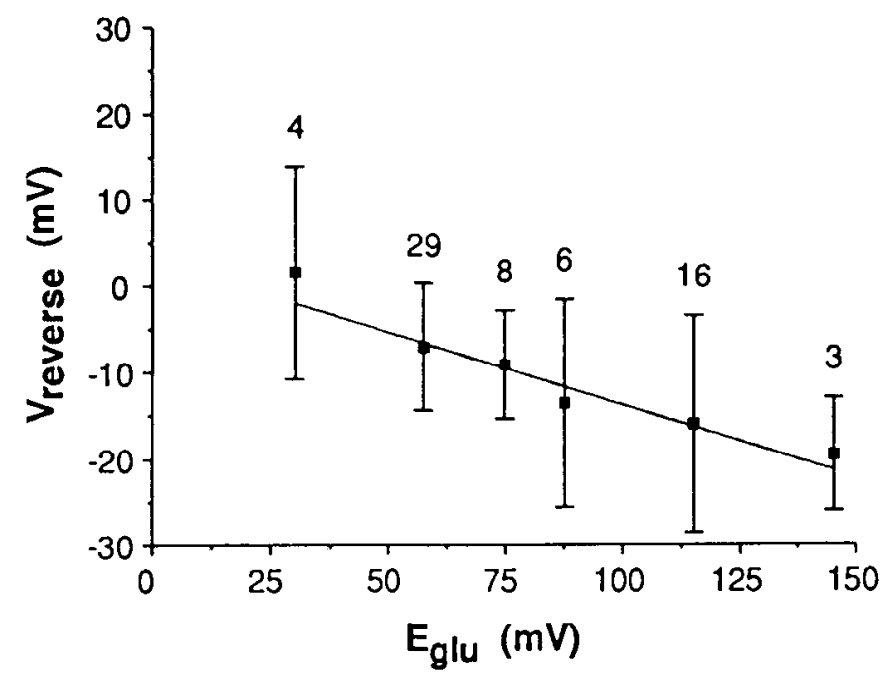

Figure 9 . Measured transporter reversal potential $\left(V_{\text {reverse }}\right)$ as a function of the glutamate equilibrium potential $\left(E_{\mathrm{glu}}\right)$. The line represents least squares fit, whose equation is $-0.185 \cdot E_{\mathrm{glu}}+3.08$. Data were collected from 40 cells. Intracellular glutamate concentration ranged from 1 to $10 \mathrm{mM}$, and extracellular glutamate concentration ranged from $10 \mu \mathrm{M}$ to $1 \mathrm{~mm}$. Points represent mean, and error bars represent SDs. Numbers above error bars represent the number of cells used for that data point.

What is the shape of such a curve? When L-glutamate is present on both the inside and outside of the membrane, the transporter will act bidirectionally, and the blocker-sensitive current will be inward over the potential range where uptake occurs, and outward where release occurs. When uptake and release are equal in magnitude, there will be no net flow through the transporter. The potential at which this occurs is the equilibrium potential for the transporter.

Currents crossing the voltage axis were indeed found, and are shown in Figure 8. These data are from the same cell as shown in Figure $7 A$. The patch pipette contained $1 \mathrm{mM}$ L-glutamate, and the bath contained $100 \mu \mathrm{M} \mathrm{L}$-glutamate. Application of DHKA, $\beta \mathrm{HA}$, and tPDC resulted in the blocking of a current that was inward when the membrane potential was negative, and outward when the membrane potential was positive. All three blocker-sensitive currents reversed near the same potential (ca. $0 \mathrm{mV}$ ), consistent with thcir action bcing specific, occurring at the same site. In most cells, both $\beta \mathrm{HA}$ and $\mathrm{tPDC}$ were less effective than DHKA at blocking the outward current (i.e., release) at positive potentials, suggesting a voltage dependence to their block effect. We have therefore restricted our studies of the transport current to the use of DHKA.

\section{Varying $\mathrm{E}_{\text {glu }}$ shifts the transporter equilibrium potential}

Since the reversal potential of the blocked current represents the equilibrium potential for the transporter, regardless of any voltage dependence that may exist for the DHKA block, Equation 2 predicts that this potential should be proportional to the $\log$ of the glutamate concentration gradient. The slope of this equation is the stoichiometrical contribution that glutamate makes to the net transported charge, and the sign is an indication of the direction of the transport of glutamate relative to the net transportcd charge (sce Discussion). This relationship is shown in Figure 9. Transporter reversal potentials were measured in a total of 40 cells, with intracellular glutamate concentrations ranging from $1 \mathrm{~mm}$ to $10 \mathrm{~mm}$ and extracellular glutamate concentrations ranging from $10 \mu \mathrm{M}$ to $1 \mathrm{~mm}$. A line has been fit to 
A

$\Gamma^{0} 1 \mathrm{mM} \mathrm{BHA}$

$-20$

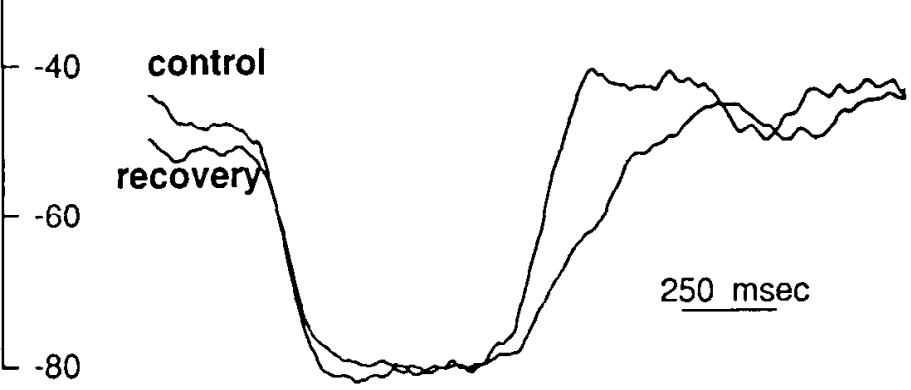

$\mathrm{V}_{\text {mem }}(\mathrm{mV})$
B

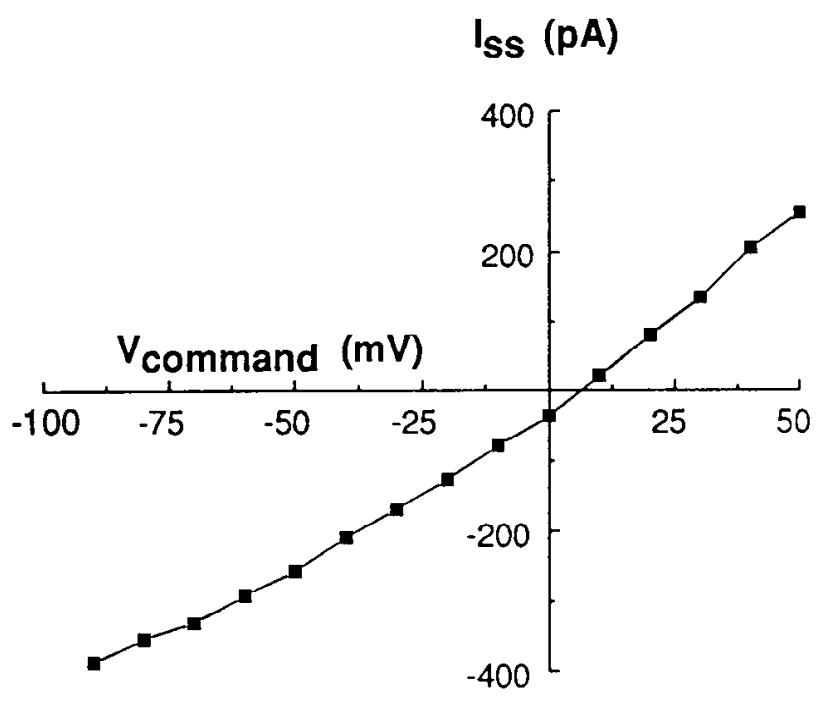

Figure 10. Effect of $1 \mathrm{~mm} \beta \mathrm{HA}$ on an identified horizontal cell in a retinal slice. $A$, Voltage recordings in response to a subsaturating, full-field, $600 \mathrm{msec}$ step of light in control Ringer's and in the presence of $1 \mathrm{~mm} \beta \mathrm{HA}$. $\beta \mathrm{HA}$ depolarized the cell and abolished the light response. Recovery trace was taken in control Ringer's following application of $\beta \mathrm{HA}$. Membrane potential is indicated at the left. $B$, Steady state current, measured under voltage clamp, generated by the application of $1 \mathrm{~mm} \beta \mathrm{HA}$ in the same cell as shown in $A$. $\beta \mathrm{HA}$ caused a conductance increase in this cell of $5.89 \mathrm{nS}$ with a reversal potential of $+9 \mathrm{mV}$.

all the data points, using the least-squares method, and the data fit a linear relationship with a negative slope reasonably well.

\section{Transport blockers block transmission to horizontal cells}

Transport blockers depolarize horizontal cells. To investigate further the role of the transporter in synaptic transmission, we looked at what effect blocking the transporter would have on transmission from photoreceptors to horizontal cells. We recorded from horizontal cells in the retinal slice, and observed the voltage response to subsaturating full-field $600 \mathrm{msec}$ flashes under current clamp in the presence and absence of the transport blockers $\beta \mathrm{HA}$ ( $1 \mathrm{mM}$ ) and DHKA ( $1 \mathrm{~mm}$ ). All experiments were done with $1 \mathrm{~mm}$ cAMP inside the pipette and $100 \mu \mathrm{M} 8 \mathrm{Br}$ cAMP in the Ringer's to reduce electrical coupling between horizontal cells (DeVries and Schwartz, 1989), and with $100 \mu \mathrm{M}$ picrotoxin in the Ringer's to reduce chemical coupling between horizontal cells (Kamermans and Werblin, 1992). Application of either blocker caused both a depolarization of the horizontal cell and a decrease in the light response. The effect of $\beta \mathrm{HA}$ in one cell is shown in Figure 10A. The degree of depolarization varied, probably depending on the relative contribution of the glutamate-elicited conductance to the total membrane conductance, but the reduction of the light response was quite consistent between cells. DHKA at $1 \mathrm{~mm}$ caused a reduction in the light response of $83.6 \pm 10.2 \%(N=6)$, whereas $1 \mathrm{mM} \beta \mathrm{HA}$ caused a complete elimination of the light response $(N=6)$. The effect of $\beta \mathrm{HA}$ gencrally showed a complete recovery, whereas a recovery following application of DHKA was more difficult to obtain.

Transport blockers increase an excitatory-type conductance. In the same six cells, we also switched to voltage clamp to see whether the application of $\beta \mathrm{HA}$ was associated with a conductance change. In all six cells, $\beta \mathrm{HA}$ resulted reversibly in an increase in conductance with a reversal potential near that $\mathrm{ex}$ - pected for a glutamate-elicited conductance. Overall, the conductance increase was $3.68 \pm 0.79 \mathrm{nS}$, with a reversal potential of $-0.35 \pm 1.55 \mathrm{mV}(N=6)$. The conductance increased by $\beta \mathrm{HA}$ in the cell from Figure $10 \mathrm{~A}$ is shown in Figure $10 B$.

These results are consistent with the notion that the role of the transporter is to remove glutamate from the cleft. Blocking the transporter would then cause the glutamate concentration in the cleft to rise, which would cause horizontal cells to depolarize. If the resulting glutamate concentration is high enough, the postsynaptic receptors will saturate, and no light response will be measurable in the horizontal cells. This is what was observed.

Transport blockers do not directly effect horizontal cells. However, it is possible that DHKA and/or $\beta$ HA was acting directly at the horizontal cell. We therefore looked at the effects of these two substances on horizontal cells when glutamate concentrations in the synaptic cleft are very small. We applied $1 \mathrm{~mm} \beta \mathrm{HA}$ and $1 \mathrm{~mm}$ DHKA in a Ringer's containing 0 calcium, 0 magnesium, and $2 \mathrm{~mm}$ cobalt, and recorded from horizontal cells under voltage clamp. Cobalt was used not only to block vesicular release from photoreceptors, but to chelate any endogenous glutamate probably to the submicromolar range (Martell and Smith, 1974). No current was ever generated by either blocker, over the entire potential range of $-100 \mathrm{mV}$ to $+40 \mathrm{mV}(N=5)$. As a further test, since $\beta \mathrm{HA}$ has been reported occasionally to be a weak NMDA agonist, we added $1 \mathrm{~mm}$ APV to the bath during an application of $1 \mathrm{mM} \beta \mathrm{HA}$, and observed no change in either the steady state polarization or the light response.

\section{Discussion}

Evidence for electrogenic transport of glutamate

Pharmacology of the glutamate-elicited current. The results described in this article suggest that the glutamate-elicited current in concs is gencrated by an clectrogenic glutamate transporter, 
and not an ion channel gated by glutamate. First, the pharmacology is consistent with the presence of a glutamate transporter. Substantial currents could be generated by the amino acids L-glutamate and aspartate in both the $\mathrm{D}$ - and L-forms in the submillimolar range (Fig. 5). Such sensitivity to various amino acids of both the $L$ - and $D$-forms is consistent with many other high-affinity glutamate transporters, including to one described in turtle photoreceptors (Tachibana and Kaneko, 1988). Although the transport of D-glutamate is generally associated with a low-affinity transporter, which has a $K_{m}$ in the low millimolar range (Benjamin and Quastel, 1976), a small response was seen in cones with $100 \mu \mathrm{M}$ D-glutamate. Therefore, either both a high- and a low-affinity transporter are present on cones, the transporter under study is less specific than others about which optical isomer of glutamate is transported, or the transport of D-glutamate is so small relative to the transport of L-glutamate through this and other high-affinity transporters that it hitherto has been unmeasured. In fact, D-glutamate has been known to interact with the high-affinity transporter in other systems, since it can inhibit the uptake of L-glutamate (Balcar and Johnston, 1972).

Furthermore, the L-glutamate-elicited current could be reduced significantly by the glutamate transport blockers DHKA, $\beta \mathrm{HA}$, and $\mathrm{tPDC}$ (Fig. 7A). None of these blockers had any effect on the cone over the same potential range when no L-glutamate was present inside or outside. The relative potency of these inhibitors was $\beta \mathrm{HA}>\mathrm{tPDC}>$ DHKA. This differs from findings in synaptosomes, where $\mathrm{tPDC}>\beta \mathrm{HA}>\mathrm{DHKA}$ (Bridges et al., 1991). However, in those studies, a submaximal inhibitor concentration of $10 \mu \mathrm{M}$ was applied. The higher concentrations that we used may account for the difference in the relative potency.

Finally, the pharmacology is inconsistent with the presence of any known glutamate receptor on the cone. The current could not be elicited by the glutamate receptor agonists kainatc, quisqualate, NMDA, or APB, nor could it be blocked by the glutamate receptor antagonists CNQX, APV, or kynurenic acid (Fig. 6).

Dependence of the glutamate-elicited current on external sodium. To date, all examples of high-affinity glutamate uptake involve the concomitant uptake of sodium (see Kanner and Schuldiner, 1987, for review). Sarantis et al. (1988) reported that when sodium was replaced by choline, a glutamate-elicited current in tiger salamander cones was no longer observed. We also find an absolute requirement for sodium, and were not able to elicit a current with glutamate when either choline or lithium was used as a substitute for sodium (S. Eliasof and F. Werblin, unpublished observations). The lack of uptake when sodium is replaced by lithium is particularly significant, since lithium is permeable through most sodium channels but does not pass through transportcrs that carry sodium.

Dependence of the transporter equilibrium potential on glutamate concentration gradient. Finally, the reversal potential of the current reduced by the transport blockers is a linear function of the $\log$ glutamate concentration gradient (Fig. 9). This dependence on the $E_{\text {glu }}$ suggests that glutamate must be moving across the membrane, and not simply gating an ion channel. Moreover, the reversal potential is inversely proportional to $E_{\mathrm{glu}}$, which implies that glutamate is moving against its electrochemical gradient. This rules out the possibility that glutamate is diffusing through an anion-selective pore. A more reasonable conclusion is that glutamate is passing across the membrane through a glutamate transporter.

\section{Magnitude of the glutamate-elicited current}

One of the most surprising results is the large size of the glutamate-elicited current. Given that a single transporter operates at a turnover rate on the order of 10,000-50,000 per second (Hille, 1992), a 500 pA current would require 60,000-300,000 transporters. At best, this many carriers would have to be densely packed over an area of several square micrometers. If, however, the transporter carried more than one net charge per cycle (e.g., more than two sodiums per glutamate), or the turnover rate was less than an order of magnitude faster than described above, the number of transporters could be reasonable. Finally, we cannot rule out the possibility that both a transporter and a channel are operating in concert, resulting in a larger glutamateelicited current (see below).

\section{Comparison with previous studies in photoreceptors}

Studies suggesting glutamate transport. Glutamate transport in photoreceptors has been described previously by others in both goldfish and turtle. Glutamate uptake was first demonstrated by Marc and Lam (1981) in goldfish. Using light microscope autoradiography, they found that, upon incubation, rods accumulated primarily $\mathrm{L}^{-}{ }^{3} \mathrm{H}$-glutamate whereas both red and green cones accumulated $\mathrm{L}^{-3} \mathrm{H}$-glutamate, $\mathrm{L}-{ }^{3} \mathrm{H}$-aspartate, and $\nu^{-3} \mathrm{H}$ aspartate. Our results are consistent; we have reported a sensitivity in cones of the tiger salamander to glutamate and both the L- and D-forms of aspartate. Although we also saw a sensitivity to D-glutamate, the rate of transport was relatively small and may not have been measurable with autoradiography.

Tachibana and Kaneko (1988) reported a glutamate-elicited current in isolated turtle rods and cones, which they concluded was principally the result of glutamate being taken up through an electrogenic glutamate transporter. They found that the current could be elicited by L-glutamate and both the $\mathbf{L}$ - and $\mathrm{D}$-forms of aspartate. They could not elicit a response with $100 \mu \mathrm{M} \mathrm{D}$-glutamate, however. Additionally, the current was not mimicked by the glutamate receptor agonists kainate, quisqualate, or NMDA, nor was it blocked by the glutamate receptor antagonist kynurenic acid.

The voltage dependence of the glutamate-elicited current in turtle was inwardly rectifying, similar to the current-voltage curve in Figure $3 B$. The affinity for glutamate in turtle $\left(K_{m}=\right.$ $40 \mu \mathrm{M})$ was lower than what we found in salamander $\left(K_{m}=10\right.$ $\mu \mathrm{M})$. This may simply reflect a species difference. In summary, the glutamate transporter described in here is similar to the one described in turtle.

Study suggesting glutamate-gated conductance. Sarantis et al. (1988) reported that the glutamate-elicited current measured in isolated tiger salamander cones was generated, not by a transporter, but by a glutamate-elicited chloride conductance. Their conclusion was based on three observations. The first was a sensitivity to kainate. These data, however, were neither shown nor described in any detail. The second was the presence of an outward current when glutamate was applied at positive potentials. The third was a shift in the apparent reversal potential of this current with a change in the chloride equilibrium potential $\left(E_{\mathrm{Cl}}\right)$.

We never observed a current due to the hath application of $100 \mu \mathrm{M}(N=13)$ or $1 \mathrm{mM}(N=4)$ kainate, nor did bath application of $100 \mu \mathrm{M}$ kainate occlude the response to $100 \mu \mathrm{M} \mathrm{L-gluta-}$ 
mate $(N=4)$. We also did not measure a response to $1 \mathrm{~mm}$ kainate when it was rapidly applied near the cell membrane by pressure ejection, to reduce possible desensitization effects $(N$ $=11$ ), although as Figure 2 demonstrates, the glutamate-elicited current was quite sustained over a long period of time. Moreover, the glutamate-elicited current was never reduced by the kainate receptor antagonist CNQX. Thus, we conclude that the glutamate-elicited current in our experiments is not the result of a kainate-sensitive receptor.

Second, a glutamate-elicited outward current is indeed not expected from an ideal transporter, since applied glutamate should be taken up, generating only an inward current. However, two possible models may explain this phenomenon. The first is based on a model for the glutamate transporter in glial cells, described by Schwartz and Tachibana (1990). They reported a similar outward current at depolarized potentials, and concluded that, in the absence of glutamate, the transporter exhibited a sodium "leak." The glutamate-elicited outward current was caused by the decrease of this inward leak when glutamate was being transported. The outward current elicited by glutamate in cones may be the result of a similar mechanism.

An alternative model is that glutamate elicits a current through a chloridc-pcrmeable channel as well as through an electrogenic transporter. This could explain the large magnitude of the glutamate-elicited current and, in addition, why the voltage dependence of the glutamate-elicited current shifts with changes in the internal chloride concentration, a phenomenon that we have also observed (data not shown). In fact, based on the existence of current fluctuations elicited by glutamate, Tachibana and Kaneko (1988) concluded that a conductance as well as a transporter exists in turtle photoreceptors, although they could not separate the two phenomena. Preliminary experiments on salamander cones have likewise not revealed two pharmacologically distinct components. An intriguing possibility is that a glutamate transporter and a chloride channel coexist as part of the same macromolecule, thus sharing the same pharmacological properties. An analogous protein, P-glycoprotein, has been expressed by the human multidrug-resistance gene MDR 1 in mouse fibroblasts (Valverde et al., 1992). P-glycoprotein is not only an ATP-dependent active transporter of hydrophobic drugs but a chloride channel as well. Furthermore, chloride channel activity was inhibited by inhibitors of the drug transporter. Such a hybrid transporter-channel molecule may be part of a new family of channel proteins, which could include the cystic fibrosis transmembrane regulator, CFTR.

\section{The transporter current-voltage curve}

The current-voltage relation generated by the external application of glutamate (Fig. $3 B$ ) is not the current-voltage curve for the transporter, although it has occasionally been assumed to be such. Instead, it represents the net effect of the complex relationship between membrane potential, the binding and release of glutamate and the other ions involved, and the translocation of the transporter across the membrane (Blatt, 1986). The inward current suggests that the net current flow opposes the flow for glutamate, which is negatively charged. That is, when glutamate is taken up, the resulting net charge flow is a positive charge moving inward. This is because the transport of glutamate is accompanied by the movement of other ions as well, such as sodium moving inward.

The current-voltage curve of the transporter is more properly derived by subtracting the glutamatc-clicited current in the pres- ence of the transport blocker from that current in the absence of the blocker, at various potentials. If the blocker's action is specific for the transporter, all other currents will be eliminated by the subtraction. When glutamate and the other required ions are present on both sides of the membrane, this curve will be the sum of two curves, one for uptake and one for release. Since the block by DHKA is not complete, then to the extent that its action is not voltage dependent, the DHKA-blocked current-voltage relation shown in Figure 8 is some fraction of the transporter current-voltage curve. Although the current through the transporter is expected to saturate at both voltage extremes, the transporter current is linear over the entire voltage range studied.

Because the net transported charge is positive (uptake is inward), uptake will be most prominent at more hyperpolarized potentials and release at more depolarized potentials. The potential where uptake and release are equal in magnitude is the equilibrium potential for the transporter. This potential is important analytically, since the equilibrium potential is the weighted sum of the equilibrium potentials of all the charged molecules that are being transported (see Eq. 2). Thus, by varying each ion in succession, the stoichiometrical coefficient can be determined for each molecule. Such a method has been used, for example, in studying the $\mathrm{Na}^{+} / \mathrm{Ca}^{2+}$ exchanger in ventricular cells (Ehara et al., 1989).

\section{Functional role of the glutamate transporter}

Role in regulating extracellular [Glu]. The onset of the light response in cells postsynaptic to the photoreceptor is generated by the removal of glutamate from the synaptic cleft (Trifonov, 1968; Ayoub et al., 1989; Copenhagen and Jahr, 1989). Since there are no enzymes in the extracellular space that will metabolically inactivate or degrade glutamate, it must be either taken up or diffused. The role of glutamate transporters in synaptic transmission is clearly demonstrated by the effect of the transporter blockers on the horizontal cell response to glutamate levels in the photoreceptor terminals. Application of the blocker (1) depolarized the horizontal cell, (2) increased a conductance very much like the glutamate-sensitive conductance expected in horizontal cells, and (3) reduced or even abolished the light response. Although we have limited our studies of postsynaptic responses to horizontal cells, we presume that a similar action would be seen in hyperpolarizing bipolar cells as well. These results indicate that glutamate transporters, under physiological conditions, are involved in the uptake of glutamate, keeping the extracellular glutamate concentration to a subsaturating, modulatable level in the dark when glutamate release is maximal. When the transporters are blocked, this uptake is blocked and the extracellular glutamate concentration rises, causing an increase in conductance, and thus depolarization, in the horizontal cell. The abolition of the light response indicates that the glutamate concentration has risen to a level that is saturating for the horizontal cell glulamate receptors. The light-induced hyperpolarization of the photoreceptors is apparently not sufficient to reduce the glutamate concentration in the cleft to a level where postsynaptic receptors are not activated.

An earlier study also looked at the effect of reducing glutamate uptake on horizontal cells in goldfish (Ishida and Fain, 1981). In this study, D-aspartate was used as an inhibitor of glutamate transport. D-Aspartate applied alone in the dark caused a small depolarization and a small increase in the light response of horizontal cells. Furthermore, D-aspartate substantially poten- 
tiated the response to application of L-glutamate, by shifting the dose-response curve for L-glutamate in the direction of lower concentrations. Although D-aspartate is transported electrogenically in turtle (Tachibana and Kaneko, 1988) as well as in salamander, it is unlikely that the effect was the result of a depolarization of the cones directly; D-aspartate was without effect in the presence of a bright background illumination, when the cones are most hyperpolarized and the transporter uptake should in fact be maximal. Instead, the most likely possibility is that $\mathrm{D}$-aspartate increased the glutamate concentration in the cleft by competing with $\mathrm{L}$-glutamate at the transporter. Initially, however, D-aspartate must not have blocked glutamate transport as effectively as $\beta \mathrm{HA}$ or DHKA, because light could still elicit a hyperpolarization in the horizontal cells. Longer applications of D-aspartate did depolarize the horizontal cell and reduce the light response, consistent with the effects described in this article for $\beta \mathrm{HA}$ and DHKA (A. Ishida, personal communication).

Role of cone versus glial cell in controlling extracellular [Glu]. Although we have demonstrated that the site of action for $\beta \mathrm{HA}$ and DHKA is not directly on horizontal cells, it is incorrect to state that it is acting solely on cones. Rods also have glutamate transporters, which are sensitive to $\beta \mathrm{HA}$ (Grant et al., 1992). Furthermore, glial cells exist in the retina and have a prominent glutamate uptake system that is largest near the photoreceptor terminals and sensitive to $\beta \mathrm{HA}$ (Brew and Attwell, 1987).

Since both glia and photoreceptors contain glutamate transporters, it is worth considering their respective roles in regulating synaptic transmission. The question of the difference between neuronal and glial uptake has been the source of much discussion (for review, see Johnson, 1978). In general, glutamate removal requires either diffusion away from the cleft, uptake into glial cells, or uptake into the presynaptic cell. Because glial cells do not have processes that enter the cone invagination (Lasansky, 1973), the glial cell transporter is probably located farther from the synaptic cleft than the cone transporter, and so glutamate uptake into glial cells will require first the diffusion of glutamate out of the invagination. However, the diffusion time is probably rapid compared to the rise time of the onset of the light response in cells postsynaptic to the photoreceptors (Copenhagen et al., 1983).

A more important consideration than distance from the release sites is the relative capacity of the transporters. At any given membrane potential, glutamate elicits a significantly larger current in salamander cones than in salamander glial cells (Brew and Attwell, 1987). If all of the measured current in cones is due to a glutamate transporter, then the cone transporter can clear glutamate from the invagination much faster than the 80 msec estimated for glial cells alone. Therefore, the rate of glutamate removal will be driven principally by the cone transporter. Such a rapid removal of glutamate by the conc transporter may be important, for example, for limiting the desensitization of postsynaptic receptors, which has been reported for both horizontal and bipolar cells (Hals et al., 1986; Gilbertson et al., 1991).

Because of the pharmacological similarity between the cone and glial glutamate transporters, our experiments have not been able to discern the specific role of each transporter in transmission to postsynaptic cells. However, the most likely scenario is that the glial cells set the overall or average glutamate concentration in the outer plexiform layer, thus controlling the gradient across, and the rate of leak out of the synaptic cleft, whereas the photoreceptor controls the more local and rapid changes in the glutamate concentration.

In conclusion, we have demonstrated the existence of an electrogenic glutamate transporter in the retinal cone of the tiger salamander. This transporter plays a very important role in regulating the glutamate concentration in the synaptic cleft. The uptake of glutamate back into the cone allows for not only a means for recycling of the glutamate for subsequent release, but also for rapid removal of the transmitter from the synaptic cleft, which may be essential for a rapid onset of the light response in postsynaptic cells. We have shown that the low extracellular concentration of glutamate maintained by the glutamate transporters in cones and/or glial cells is essential for normal synaptic transmission to postsynaptic cells.

\section{References}

Ayoub GS, Korenbrot JI, Copenhagen DR (1989) Release of endogenous glutamate from isolated cone photoreceptors of the lizard. Neurosci Res [Suppl] 10:S47-S56.

Balcar VJ, Johnston GAR (1972) The structural specificity of the high affinity uptake of L-glutamate and L-aspartate by rat brain slices. $J$ Neurochem 19:2657-2666.

Benjamin AM, Quastel JH (1976) Cerebral uptakes and exchange diffusion in vitro of $L-$ and D-glutamates. J Ncurochem 26:431-441.

Blatt MR (1986) Interpretation of steady-state current-voltage curves: consequences and implications of current subtraction in transport studies. J Membr Biol 92:91-110.

Brew H, Attwell D (1987) Electrogenic glutamate uptake is a major current carrier in the membrane of axolotl retinal glial cells. Nature 327:707-709.

Bridges RJ, Stanley MS, Anderson MW, Cotman CW, Chamberlin R (1991) Conformationally defined neurotransmitter analogues. Selective inhibition of glutamate uptake by one pyrrolidine-2,4-dicarboxylate diastereomer. J Med Chem 34:717-725.

Copenhagen DR, Jahr CE (1989) Release of endogenous excitatory amino acids from turtle photoreceptors. Nature 341:536-539.

Copenhagen DR, Ashmore JF, Schnapf JK (1983) Kinetics of synaptic transmission from photorcceptors to horizontal and bipolar cells in turtle retina. Vision Res 23:363-369.

DeVries SH, Schwartz EA (1989) Modulation of an electrical synapse between solitary pairs of catfish horizontal cells by dopamine and second messengers. J Physiol (Lond) 414:351-375.

Ehara T, Matsuoka S, Noma A (1989) Measurement of reversal potential of $\mathrm{Na}^{+}-\mathrm{Ca}^{2+}$ exchange current in single guinea-pig ventricular cells. J Physiol (Lond) 410:227-249.

Fenwick EM, Marty A, Neher E (1982) A patch-clamp study of bovine chromaffin cells and of their sensitivity to acetylcholine. J Physiol (Lond) 331:577-598.

Gilbertson TA, Scobey R, Wilson M (1991) Permeation of calcium ions through non-NMDA glutamate channels in retinal bipolar cells. Science 251:1613-1615.

Grant GB, Eliasof S, Werblin FS (1992) Sodium glutamate cotransporter in rod terminals is essential for rod input to horizontal cells of the tiger salamander. Invest Ophthalmol Vis Sci 33:3171.

Hals G, Christensen T, O’Dell T, Christensen M, Shingai R (1986) Voltage-clamp analysis of currents produced by glutamate and some glutamate analogues on horizontal cells isolated from the catfish retina. J Neurophysiol 56:19-31.

Hamill OP, Marty A, Neher E, Sakmann B, Sigworth FJ (1981) Improved patch-clamp techniques for high resolution current recording from cells and cell-free membrane patches. Pfluegers Arch 391:85-100.

Hille B (1992) Ionic channels of excitable membranes, 2d ed. Sunderland, MA: Sinauer.

Ishida AT, Fain GL (1981) D-Aspartate potentiates the effects of Lglutamate on horizontal cells in goldfish retina. Proc Natl Acad Sci USA 78:5890-5894.

Iversen LL (1971) Role of transmitter uptake mechanisms in synaptic neurotransmission. Br J Pharmacol 41:571-591.

Johnson JL (1978) The excitant amino acids glutamic and aspartic acid as transmitter candidates in the vertebrate central nervous system. Prog Neurobiol 10:155-202. 
Johnston GAR, Kennedy SME, Twitchin B (1979) Action of the neurotoxin kainic acid on high affinity uptake of $\mathbf{L}$-glutamic acid in rat brain slices. J Neurochem 32:121-127.

Kamermans M, Werblin F (1992) GABA-mediated positive autofeedback loop controls horizontal cell kinetics in tiger salamander retina. J Neurosci 12:2451-2463.

Kanner BI, Schuldiner S (1987) Mechanism of transport and storage of neurotransmitters. CRC Crit Rev Biochem 22:1-38.

Lasansky A (1973) Organization of the outer synaptic layer in the retina of the larval tiger salamander. Philos Trans $\mathrm{R}$ Soc Lond [Biol] 265:471-489.

Marc RE, Lam DMK (1981) Uptake of aspartic and glutamic acid by photoreceptors in goldfish retina. Proc Natl Acad Sci USA 78 7185-7189.

Martell AE, Smith RM (1974) Critical stability constants, Vol I. New York: Plenum.

Sarantis M, Everett K, Attwell D (1988) A presynaptic action of glutamate at the cone output synapse. Nature $332: 451-453$.
Schwartz EA, Tachibana M (1990) Electrophysiology of glutamate and sodium co-transport in a glial cell of the salamander retina. J Physiol (Lond) 426:43-80.

Tachibana M, Kaneko A (1988) L-Glutamate-induced depolarization in solitary photoreceptors: a process that may contribute to the interaction between photoreceptors in situ. Proc Natl Acad Sci USA $85: 5315-5319$

Trifonov YA (1968) Study of synaptic transmission between the photoreceptor and the horizontal cell using electrical stimulation of the retina. Biofizika 13:809-817.

Valverde MA, Díaz M, Scpúlveda FV, Gill DR, Hyde SC, Higgens CF (1992) Volume-regulated chloride channels associated with the human multidrug resistance P-glycoprotein. Nature 355:830-833.

Werblin FS (1978) Transmission along and between rods in the tiger salamander retina. J Physiol (Lond) 280:449-470. 